\title{
ENFERMEDAD PROFESIONAL DE LOS TRABAJADORES DEL SECTOR SALUD POR COVID-19
}

\section{OCCUPATIONAL DISEASE OF HEALTH SECTOR WORKERS DUE TO COVID-19}

${ }^{1}$ Maestramente de Derecho por el Centro Universitario del Sur de la Universidad de Guadalajara. Correo: veneranda. sanchezmd2019@gmail.comｈttps://orcid.org/0000-00024923-9317

2 Maestro en Derecho, docente en el Centro Universitario del Sur de la Universidad de Guadalajara. Correo: uzziel. guerrero@academicos.udg.mx

${ }^{3}$ Maestro en Derecho. Abogando postulante en materia civil. Correo.gilberto_1949@hotmail.com

${ }^{4}$ Doctor en Psicología. Profesor e Investigador en el Centro Universitario del Sur de la Universidad de Guadalajara. Correo: mascampas@gmail.com https://orcid.org/0000-00026750-2713. Autor de Correspondencia: Centro Universitario del Sur. Av. Enrique Arreola Silva No. 883, colonia centro C.P. 49000, Ciudad Guzmán, Jalisco, México. Teléfono: +52

Veneranda Sánchez Ortega ${ }^{1}$

Cesar Uzziel Guerrero Ochoa² Gilverto Del Toro Barajas ${ }^{3}$ Marco Antonio Santana Campas ${ }^{4}$ (341) 575 2222, Fax: 01 (341) 5752223.

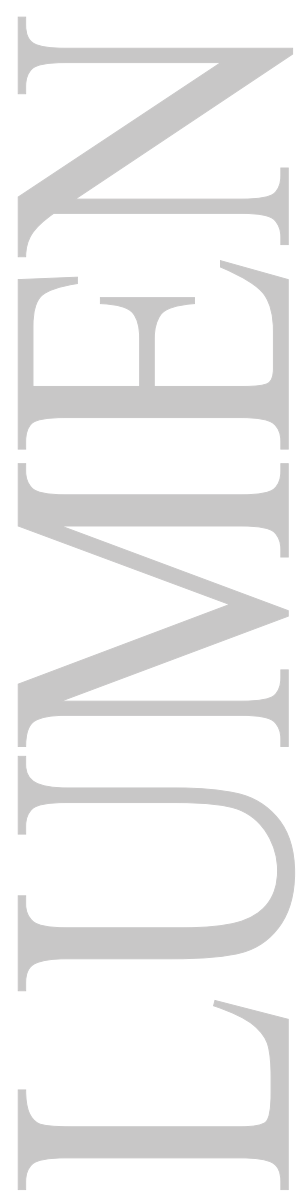




\title{
ENFERMEDAD PROFESIONAL DE LOS TRABAJADORES DEL SECTOR SALUD POR COVID-19
}

\author{
OCCUPATIONAL DISEASE OF HEALTH SECTOR \\ WORKERS DUE TO COVID-19
}

\author{
Veneranda Sánchez Ortega \\ Cesar Uzziel Guerrero Ochoa \\ Gilverto Del Toro Barajas \\ Marco Antonio Santana Pampas
}

\begin{abstract}
RESUMEN
Ante la situación apremiante que desarrolló la enfermedad viral mejor conocida como COVID- 19, sirvió para hacer notar la falta de regulación laboral en México como enfermedad profesional para los prestadores de servicios del Sector Salud. Método: Investigación Cualitativa, mediante el análisis de publicaciones de carácter científico, que abordan el tema de manera mundial la cuestión de contagio por Covid-19 en el personal de atención médica. Resultados: Las investigaciones que tratan acerca del tema Covid-19 y el personal del sector salud, se enfocan en la situación anímica del trabajador, siendo contadas las investigaciones que tratan a fondo la situación legal y laboral de los trabajadores al servicio de la salud. Conclusión: La falta de regulación de la Enfermedad Covid-19, como enfermedad profesional en la tabla de enfermedades profesionales señalada en el artículo 513 de la Ley Federal del trabajo, deja en desprotección a los trabajadores del Sector Salud.
\end{abstract}

\section{PALABRAS CLAVES}

Trabajadores del sector salud, enfermedad profesional, Covid-19, derechos laborales.

\begin{abstract}
Faced with the pressing situation that developed the viral disease better known as COVID-19, it served to highlight the lack of labor regulation in Mexico as an occupational disease for providers of services in the Health Sector. Method: Qualitative Research, through the analysis of scientific publications, which address the issue worldwide, the issue of contagion by Covid-19 in health care personnel. Results: The investigations that deal with the issue of Covid-19 and the personnel of the health sector, focus on the mental situation of the worker, being counted the investigations that deal in depth with the legal and labor situation of the workers in the health service. Conclusion: The lack of regulation of Covid-19 disease, as an occupational disease in the table of occupational diseases indicated in article 513 of the Federal Labor Law, leaves workers in the Health Sector unprotected.
\end{abstract}

\section{KEY WORDS}

Health sector workers, occupational disease, Covid-19, labor rights

\section{INTRODUCCIÓN}

Ante la situación apremiante que desarrolló la enfermedad viral mejor conocida como COVID- 19, sirvió para una cosa, hacer notar las deficiencias de la regulación laboral en México saliendo a relucir tantas áreas de oportunidad entre ellas la situación en la que se encuentran del sector salud por covid-19 los trabajadores del sector salud, quienes son los primeros en atender la enfermedad, y en los últimos que se contempló la situación de alto riesgo por la que están pasando, que encontrándose en su fuente de trabajo no se define bien si en caso de ser contagiados por dicho virus, se les considere como enfermedad general o enfermedad profesional. 
Sin embargo el Instituto Mexicano del Seguro Social (IMSS), a través de la Dirección de Prestaciones Económicas y Sociales, emitió con fecha 03 de abril del año 2020 la circular 099001 300000 / 068 / 2020, en la cual se enuncian los Criterios de calificación para casos con Coronavirus (COVID-19) como Enfermedad de Trabajo; Lineamientos que deberán seguir las autoridades del Instituto, previstas en el "Procedimiento para la dictaminación y prevención de las enfermedades de trabajo" clave 2320-003-010, esto a grandes rasgos, considerando únicamente como criterio para que sea calificada como Enfermedad de Trabajo la relación causa-efecto, trabajo-daño para los trabajadores del propio Instituto diagnosticados de infección por coronavirus (COVID-19).

Por lo que en caso de muerte por dicho contagio los derechos de los trabajadores del Instituto así como beneficiarios quedarían resguardados; pero no fue así en todos los sectores que brindan atención médica, esto es, el Instituto de Seguridad y Servicios Sociales de los Trabajadores del Estado (ISSSTE), el Instituto de Seguridad Social, para las Fuerzas Armadas Mexicanas (ISSFAM), la Secretaria de la Defensa Nacional (SEDENA), la Secretaria de Marina (SEMAR) quienes brindan de manera subrogada atención médica a los integrantes del ejército Mexicano, y el Instituto Nacional de Bienestar (INSABI).

Ahora bien hablando de números la investigación denominada "En México el personal de salud muere seis veces más que en China por Covid-19" realizada por la Asociación Mexicanos contra la corrupción y la impunidad, manifiesta que el porcentaje de contagio entre el personal médico es del $23 \%$ sobre el total de contagios a nivel nacional, este dato es al día 11 de Mayo del año 2020, dicha información refiere que la obtiene de la página del Sistema Nacional de Vigilancia Epidemiológica la cual solo reporta los porcentajes del Estado de México, en cuanto al resto de los Estados de la república no está disponible la información al respecto, para ser consultada en los sititos públicos del gobierno federal.

Entonces, al hacer referencia a los trabajadores del sector salud, es hablar de médicos, enfermeras, personal de laboratorio y gabinete, administrativo, asistentes médicos, trabajo social, terapia respiratoria, dietología, servicios de intendencia, auxiliares del servicio de patología y cualquier otro puesto que se encuentre en contacto con pacientes contagiados en los servicios de atención médica y personal de aseo de las dependencias que brindan atención médica, los cuales son propensos a adquirir el virus por motivo del desempeño de su trabajo, así lo refiere en la publicación "Sentimientos relatados por los trabajadores de la salud frente a la epidemia de SIDA" Villarinho (2016), menciona que los trabajadores de la salud manifiestan su preocupación al estar sujetos al riesgo de contagio, por encontrarse directamente vinculados a la exposición de fluidos corporales emitidos por la atención a pacientes que requieren de asistencia médica.

Ya lo menciona Fernándes (2020) la salud del trabajador dedicado a la atención medica se vuelve un factor que demanda atención a nivel mundial y se entiende como la unión de varias actividades que tienen como fin el dar a conocer las medidas de protección, vigilancia y recuperación ante las enfermedades de carácter epidemiológico y sanitario de quienes trabajan y están sujetos a lesiones o riesgos resultantes de sus condiciones laborales y de las actividades que les demanden.

Esta situación en la que el trabajador de la salud es propenso a adquirir una enfermedad por contagio y que su situación laboral se encuentre sujeta a la incertidumbre legal no es una cuestión resiente, Tomasi (2020) refiere que en la historia, han existido otras epidemias, pero en las que ya se contaba asistencia médica resaltan la gripe española en el año 1918 al 1919 con cincuenta millones de muertos; la gripe asiática del año 1957 al 1958 con más de un millón cien mil muertos, la gripe de Hong Kong 1968 al 1969 con dos millones de muertos, Síndrome de Inmunodeficiencia Adquirida, la cual lleva hasta la fecha treinta millones de muertos, la Gripe Porcina del año 2009 al 2010 con doscientos mil muertos, Ébola 2012 al 2016 con catorce mil muertos, y en todas ellas se dio el contagio al personal del sector salud. 
Entonces referir que el virus SARS-CoV-2, fue un detonante para señalar la falta de resguardo de los derechos laborales de los trabajadores del sector salud, seria desconocer la situación de riesgo de la que han sido sujetos por tantas décadas.

La situación es que los riesgos de morir a causa de Covid-19 son elevados en el campo laboral de la asistencia médica, y que al no encontrarse como enfermedad profesional en la tabla de enfermedades de trabajo, señaladas en el artículo 513 de la Ley Federal del Trabajo numeral 136, dicha falta regulatoria para la protección de los derechos laborales de los trabajadores del sector salud se encuentra sujeto a la subjetividad, exceptuando al Instituto Mexicano del Seguro Social, siendo permisiva la situación a los patrones para que la enfermedad sea considerada como enfermedad general y no verse en la obligación de cambiar la prima de riesgo de trabajo.

\section{CONTENIDO}

\section{Pregunta(s) de investigación}

¿En qué situación legal-laboral quedan los trabajadores del Sector Salud al contraer el contagio COVID-19?

¿Cómo se encuentran respaldados los derechos de los Trabajadores del Sector Salud en materia de Seguridad Social por contagio de Covid-19?

\section{Análisis teórico jurídico}

Si bien la Enfermedad Profesional se encuentra sujeta a la valorización de un médico, con especialidad en Salud en el Trabajo, para que pueda determinarse como tal, esta enfermedad debe encontrarse regulada en la Ley Federal del Trabajo en la tabla de Enfermedades profesionales, en la cual aparte de señalar la enfermedad, también señala a los sujetos laborales candidatos a que la enfermedad se les atribuya como profesional

Es entonces que el Instituto Mexicano del Seguro Social, a través de la Dirección de Prestaciones Económicas y Sociales, emitió la circular 099001300000 / 068/2020 para especificar la determinación de enfermedad profesional por contagio de COVID-19, y que, aunque no se encuentre señalada en la tabla de enfermedades profesionales de la Ley Federal del Trabajo, el Instituto responde ante las necesidades legales-laborales de sus trabajadores al servicio de la salud.

En este sentido, el criterio señalado en la circular 099001300000 / 068 / 2020 refiere la garantía laboral y de asistencia médica para los trabajadores del Instituto Mexicano del Seguro Social, por lo que el problema se encuentra en la falta regulatoria de la enfermedad profesional por contagio de COVID-19 dentro de la tabla de enfermedades de trabajo contenidas en el artículo 513 de la Ley Federal del Trabajo, por lo que se presta a la subjetividad el resguardo del derecho de los trabajadores al servicio de la salud que no se encuentran sujetos a la Ley del Seguro Social, esto es, los empleados del Instituto de Seguridad Social y Servicios Sociales de los Trabajadores del Estado (ISSSTE), quienes atienden a los trabajadores al Servicio del Gobierno Federal, la Secretaria de la Defensa Nacional (SEDENA), así como la Secretaria de Marina (SEMAR), quienes brindan de manera subrogada atención médica a los integrantes de las Fuerzas Armadas de México, el Instituto de Salud para el Bienestar (INSABI) quien atiende a las personas que no cuentan con un trabajo formal que los pueda tener asegurados en las Instituciones ya señaladas.

Viéndolo desde una jerarquía legal, en la Declaración Internacional de Derechos Humanos en su artículo 22 menciona... 
Articulo 22.-Toda persona, como miembro de la sociedad, tiene derecho a la seguridad social, y a obtener, mediante el esfuerzo nacional y la cooperación internacional, habida cuenta de la organización y los recursos de cada Estado la satisfacción de los derechos económicos, sociales y culturales, indispensables a su dignidad y al libre desarrollo de su personalidad.

De igual forma en el convenio sobre seguridad social (norma mínima), 1952 (num.102) en su apartado VI referente a Prestaciones en Caso de Accidente del Trabajo y de Enfermedad Profesional, en su artículo 31 refiere lo siguiente

Articulo 31.- Todo miembro para el que esté en vigor esta parte del convenio deberá garantizar a las personas protegidas la concesión de prestaciones en caso del accidente del trabajo y de enfermedad profesional...

En cuanto a la Constitución Política de los Estados Unidos Mexicanos en su artículo 123 Apartado B Fracción XI Inciso a) menciona que...

Artículo 123. Entre los Poderes de la Unión y sus Trabajadores... XI.- La seguridad social se organizará conforme a las siguientes bases mínimas: a) Cubrirá los accidentes y enfermedades profesionales; las enfermedades no profesionales y maternidad; jubilación, la invalidez, vejez y muerte.

Ahora bien, tocante a la Ley Federal del Trabajo en su Artículo 475 menciona...

Artículo 475.- Enfermedad de trabajo es todo estado patológico derivado de la acción continuada de una causa que tenga su origen o motivo en el trabajo o en el medio en que el trabajador se vea obligado a prestar sus servicios.

En tanto su artículo 513 hace referencia a la tabla de Enfermedades profesionales, la cual a la letra dice...

Artículo 513.- La Secretaria del trabajo y Previsión Social actualizara las tablas de enfermedades de trabajo y de evaluación de las incapacidades permanentes resultante de los riesgos de trabajo, mismas que se publicaran en el Diario Oficial de la Federación y serán de observancia general en todo el territorio nacional, para este efecto dicha dependencia escuchara la opinión de la Comisión Consultiva Nacional de Seguridad y Salud en el Trabajo, de la Secretaria de Salud, de la Secretaria de Medio Ambiente y de Recursos naturales, así como de especialistas en la materia.

Por lo que la tabla de enfermedades de la Ley Federal del Trabajo en su apartado Infecciones, parasitosis, micosis y virosis, numeral 136 refiere lo siguiente.

Enfermedades generalizadas o localizadas provocadas por acción de bacterias, parásitos, hongos y virus.

136. Virus (Hepatitis, enterovirosis, rabia, psitacosis, neumonías a virus, mononucleosis infecciosa, poliomielitis y otras).

Médicos, enfermeras, y personal de limpieza en hospitales y sanatorios, personal de laboratorio y análisis clínicos, personal de bancos de sangre, siempre que se identifique el agente causal en el paciente y en el sitio de trabajo

Entonces se señala de manera clara lo que es una enfermedad de trabajo, y el apartado donde se señala las enfermedades por virus catalogadas como enfermedades profesionales 
Mientras la Ley del Instituto Mexicano del Seguro Social señala de igual manera lo que es una enfermedad de trabajo ...

Artículo 43. Enfermedad de trabajo es todo estado patológico derivado de la acción continuada de una causa que tenga su origen o motivo en el trabajo, o en el medio en que el trabajador se vea obligado a prestar sus servicios. En todo caso, serán enfermedades de trabajo las consignadas en la Ley Federal del trabajo.

Ahora bien, antes de referir a las leyes reglamentarias de las otras instituciones que dan atención médica, será bueno señalar la circular 099001300000 / 068 / 2020 del Instituto Mexicano del Seguro Social en la que señala que el contagio por Covid-19 entre los integrantes del personal que presta el servicio de atención medica será considerado como enfermedad profesional.

En mencionada circular establece como Objetivo General

Determinar los criterios que permitan al personal médico de los Servicios de Salud en el Trabajo establecer la relación causa-efecto, trabajo-daño, en los casos de probable enfermedad de trabajo por Coronavirus SARS-CoV-2 (COVID-19) que se presenten, a fin de que sean calificados como enfermedad de trabajo cuando proceda y se fortalezcan las medidas preventivas en contra del contagio del citado virus.

Entonces de esta manera queda claro, que el contagio de la enfermedad denominada COVID- 19, será evaluada como enfermedad laboral en el personal médico, del Instituto Mexicano del Seguro Social, aplicando los criterios de la circular 099001300000 / 068 / 2020

Entonces, en cuanto a la Ley del Instituto de Seguridad y Servicios Sociales de los Trabajadores del Estado, menciona de manera general que los accidentes y enfermedades se consideran riesgos de trabajo, tal y como lo refiere en su artículo $56 \ldots$

Artículo 56.- Para efectos de esta Ley, serán reputados como riesgos de trabajo los accidentes y enfermedades a que están expuestos los Trabajadores en el ejercicio o con motivo del trabajo.

Mientras que la Secretaria de la Defensa Nacional, así como la Secretaria de Marina, quienes brindan de manera subrogada atención médica a los integrantes de las Fuerzas Armadas de México, y el Instituto de Salud para el Bienestar, no refieren en sus leyes, un apartado que aluda a las enfermedades profesionales, y siendo que también estas instituciones atienden personas contagiadas con el virus ya referido con anterioridad, es entonces que al no estar contemplado en sus leyes, se presta a la negativa de considerar el contagio como una enfermedad profesional.

Los trabajadores de dichas instituciones necesitan saberse respaldados en caso de ser contagiados y contar con prestaciones que garanticen su subsistencia en caso de contagio el cual llegaría a limitar laboralmente; o si se tratara de muerte del trabajador saber en qué situación quedan protegidos sus beneficiarios, porque al no señalarse directamente como enfermedad laboral en la tabla de enfermedades profesionales señaladas en el artículo 513 de la Ley Federal del Trabajo, deja una laguna legal, en la cual el patrón directo del trabajador al servicio de la salud, se deslinda de la responsabilidad por la enfermedad contraída, y con esto no incrementar los gastos que pudiera generarle al hacer frente a una enfermedad laboral, aunado a que las prestaciones a otorgar serian nulas si no reúnen las semanas necesarias para obtener una pensión por viudez y orfandad en su caso por ascendientes al no considerarse el contagio en el rubro de enfermedad profesional.

Es por esto que el analizar al virus COVID-19 como enfermedad profesional dentro de la regulación laboral en México, se consideraría un esclarecimiento en cuanto a la situación de los trabajadores al servicio de la salud, y que al ser un derecho constitucional, debe especificarse en la Ley Federal 
del Trabajo que dicha enfermedad se debe considerar como enfermedad profesional, para que los trabajadores del sector salud tengan la certeza de que sus derechos laborales se encuentran salvaguardados a pesar de las circunstancias medicas a las que se encuentran expuestos.

Al tratarse de una situación novedosa, la cual inicio en diciembre del año 2019, los artículos derivados del tema COVID-19 son numerosos, pero ya tratándose de la situación laboral-legal que alberga a los trabajadores del sector salud son muy contados pero muy sustanciosos.

Martí-Amengual (2020) refiere que, al estar contemplada como enfermedad infectocontagiosa, afecta directamente a los profesionales sanitarios que se encuentran en la atención primaria de los pacientes detectados con COVID-19. Esto refleja que en España ya se considera como enfermedad laboral, puesto que se vio la necesidad de hacerlo desde el momento en que los trabajadores del sector salud comenzaron a sufrir las consecuencias de atender a personas infectadas.

Los trabajadores de este medio, son considerados la esperanza ante la situación que apremia, y que al no respetarle sus derechos se estaría ante una crisis de nulo personal que pueda atender la demanda de atención médica. Sacristan (2020) Aunque los médicos, enfermeras, y encargados de laboratorios y análisis clínicos son conscientes del riesgo que corren, aun así, salen todos los días a atender su vocación, y dar pronto auxilio a las personas que ya se encuentran afectadas por dicha enfermedad, pero lo más preocupante que de las personas contagiadas, los trabajadores del sector salud representan el $15 \%$ de todos los infectados en España.

La entregada vocación de los trabajadores de la salud no exime del estrés que conlleva toda esta situación; Lai (2020) El temor a ser contagiados, contagiar a sus familias, la señalización que sufren por parte de personas que no captan el problema de forma correcta, todo eso implica una situación de estrés a largo plazo, la cual, los trastornos de salud mental, también debería considerarse como enfermedad laboral.

Lo anterior desencadena en una clara violación de los derechos de los trabajadores del sector salud, como lo refiere Barreto (2020) en su publicación "repercusiones de la pandemia covid-19 en la violencia laboral institucional a profesionales de enfermería: covid19 y violencia laboral vida por la enfermería" expone que la violación a los derechos de los trabajadores por parte de la institución para la cual trabajan es observado ahora con esta nueva enfermedad Covid-19, y en la cual se debe de hacer un verdadero reforzamiento legal para la protección de los derechos de los trabajadores.

La situación es que la enfermedad covid-19 solo fue el detonante para analizar la situación, de que el derecho laboral para los trabajadores del Sector Salud se encuentra atrasado en cuanto a enfermedades laborales, Preti (2020) manifiesta que han existido otros brotes de índole infecciosas que atacan el sistema respiratorio, como lo son el Síndrome Respiratorio Agudo Severo detectado por primera vez en el año 2002, la influenza A/H1N1 en el año 2009-2010, en si la situaciones que desembocan en pandemia mundial, requieren de la inmediata intervención del personal médico; dichas enfermedades llegaron a México, y nunca se consideró el ingresarlos a la tabla de enfermedades profesionales.

Por último y para dar respuesta a la primer pregunta planteada en esta investigación se menciona que actualmente la regulación laboral en México no contempla como enfermedad laboral el contagio por COVID-19, lo que afecta directamente a los trabajadores del sector salud, y que aunque el Instituto Mexicano del Seguro Social, contempla de manera interna la calificación de Covid-19 como enfermedad laboral para sus trabajadores internos, esto no se ha replicado en la normatividad laboral general, por lo que en pocas palabras, la situación de los trabajadores del sector salud quedan desprotegidos laboralmente al contraer la enfermedad, puesto que en el caso de ser contagiados, solo se les contempla como enfermedad general. 
En cuanto a la segunda pregunta de investigación se concluye que los derechos de los trabajadores del sector salud, se encuentran garantizados en la Ley Federal del Trabajo, y por sus propias leyes internas normativas, pero en la actualidad a causa de las necesidades que desencadeno la enfermedad mejor conocida como COVID-19, que la tasa de mortalidad en los trabajadores del sector salud ha sido muy notoria, resalta a la luz, que al morir, se determina que murió de enfermedad general, quedando violentados los derechos del trabajador, puesto que su entorno por la situación que se presta, se debe considerar que el trabajador falleció de enfermedad laboral, pero mientras no se encuentre regulada la enfermedad infectocontagiosa, el trabajador del sector salud, al padecer o morir a causa de enfermedad infectocontagiosa no le serán garantizados sus derechos como enfermedad de trabajo.

\section{CONCLUSIONES}

1. Que, de la información recopilada para la elaboración del presente artículo, se desprende que lo que más preocupa a los trabajadores del sector salud es el estrés que se desarrolla por todo lo que conlleva la asistencia médica en el tratamiento de pacientes contagiados por Covid-19, pero que muy pocos están informados o se interesan por que se les reconozcan sus derechos en materia legal-laboral.

2. Que analizando la Circular 099001300000 / 068 / 2020 emitida por el Instituto Mexicano del Seguro Social se observa un paso muy importante en la seguridad social de los trabajadores de dicho Instituto, al calificarse como Enfermedad Laboral, el contagio por Covid- 19

3. Los trabajadores de los demás institutos encargados de dar asistencia médica al resto del sector laboral, aun no cuentan con un parámetro o indicación para que el contagio se les tenga contemplado como enfermedad profesional, y por ende se deja en absoluta desprotección a dichos trabajadores, siendo que son la primera línea de defensa para la atención medica de personas contagiadas.

4. Es necesario implementar en la Ley Federal del Trabajo, en su artículo 513 referente a la tabla de enfermedades apartado Infecciones, parasitosis, micosis y virosis numeral 136 el que se señale la enfermedad por contagio Covid-19, como enfermedad de trabajo, y que aluda a los propensos a dicho contagio a todos los trabajadores del sector salud, para que de esta forma no sea un derecho exclusivo de los trabajadores al servicio del Instituto Mexicano del Seguro Social.

\section{Limitantes:}

En la presente investigación se dejó de lado, pero no por esto deja de ser importante, el analizar en la tabla de enfermedades profesionales del artículo 513 de la Ley Federal del Trabajo, en su apartado "Infecciones, Parasitosis, Micosis y Virosis", que siendo un total de 21 enfermedades las cuales todas son atendidas por personal médico que en solo 5 enfermedades sean considerada propias del personal al servicio de la salud.

Así también respecto de la información ya recopilada se rescata que el personal de atención medica es propenso a padecer estrés, puesto que son muchos los factores que influyen en su desequilibrio emocional, y que, al no encontrarse en la tabla de Enfermedades Profesionales, se atenta a los derechos laborales del sector salud.

De igual forma, el que la enfermedad COVID-19, también sea considerada como enfermedad profesional para el resto de la población laboral. 


\section{REFERENCIAS}

- AGUILAR, S. (2020). En México el personal de salud muere seis veces más que en China por Covid-19. Mexicanos Contra la Corrupción y la Impunidad. Recuperado de: https:// contralacorrupcion.mx/contagios-medicos-covid-19/

- BARRETO, F., VIDAL, J.., MOREIRA, R., Y OLIVEIRA, A., (2020). Repercussões Da Pandemia De Covid-19 Na Violência Laboral Institucional Aos Profissionais De Enfermagem: Covid19 E Violência Laboral Vivida Pela Enfermagem. Preprints.scielo.org. Recuperado de: https://doi.org/10.1590/scielopreprints.934

- CARBONETTI, A. (2010). Historia de una epidemia olvidada: La pandemia de gripe española en la Argentina, 1918-1919. Desacatos, (32), 159-174. Recuperado de: http://www.scielo.org. $\mathrm{mx} / \mathrm{scielo}$.php?script=sci_arttext\&pid=S1607050X2010000100012\&lng=es \&tlng=es.

- FERNANDES, M. \& ALVES A. (2020). Salud mental y estrés ocupacional en trabajadores de la salud a la primera línea de la pandemia de COVID-19. Revista Cuidarte, 11(2). Recuperado de: http://dx.doi.org/10.15649/cuidarte.1222

- INSTITUTO MEXICANO DEL SEGURO SOCIAL (2020) Criterios de calificación para casos con Coronavirus (COVID-19) como Enfermedad de Trabajo. (09 9001300000 / 068 / 2020) Recuperado de: http://www.amcp.mx/wpcontent/uploads/2020/04/covidenfermedadlaboral. pdf

- MARTÍ, A., SANZ, G., \& ARIMANY, M. (2020). Valoracion medicolegal dela infección por COVID-19 en el ámbito laboral. Revista Española de Medicina Legal, 46(3), 146-152. Recuperado de: https://doi.org/10.1016/j.reml.2020.05.011

- POSADA, Z., YEPES, D., \& PATIÑO O., (2020). Amor, riesgo y Sida: hombres que tienen sexo con hombres. Estudios Feministas, 28(1), Recuperado de: http://dx.doi.org/10.1590/18069584- 2020v28n150443

- PRETI, E., DI MATTEI, V., PEREGO, G., FERRARI, F., MAZZETTI, M., TARANTO, P. \& CALATI, R. (2020). The Psychological Impact of Epidemic and Pandemic Outbreaks on Healthcare Workers: Rapid Review of the Evidence. Current Psychiatry Reports, (43). Recuperado de: https://link.springer.com/article/10.1007/s11920-020-01166-z

- SACRISTÁN, J., \& MILLÁN, J. (2020). El médico frente a la COVID-19: lecciones de una pandemia. Educación Médica, 21(4), 265-271. Recuperado de: https://doi.org/10.1016/j. edumed.2020.06.002

- TOMASI, S. (2020). Historia de las pandemias mundiales y la economía. Magatem V.(82), 1-37. Recuperado de: https://www.magatem.com.ar/HISTORIA-DE-LASPANDEMIAS- MUNDIALES-Y-LA-ECONOMIA.pdf

- VIEIRA, V.M. \& ITAYRA, P.M. (2016). Sentimentos relatados pelos trabalhadores da saúde frente á Epidemia da Aids (1986-2006). Texto \& Contexto - Enfermagem, 25(1), Recuperado de: https://doi.org/10.1590/0104-07072016000010013

\section{REFERENCIAS LEGALES}

- Congreso de la Unión (2019). Constitución Política de los Estados Unidos Mexicano. México Recuperado de: http://www.diputados.gob.mx/LeyesBiblio/pdf_mov/Constitucion_Politica.pdf

- Congreso de la Unión (2019). Ley del Instituto de Seguridad y Servicios Sociales de los Trabajadores del Estado. México. Recuperado de:http://www.diputados. gob.mx/LeyesBiblio/pdf/LISSSTE_040619.pdf

- Congreso de la Unión (2019). Ley del Seguro Social. México. Recuperado de: http://www. imss.gob.mx/sites/all/statics/pdf/leyes/LSS.pdf

- Congreso de la Unión. (2019). Ley Federal del Trabajo. México. Recuperado de: http://www. diputados.gob.mx/LeyesBiblio/pdf/125_020719.pdf 
- Organismo Nacional de los Derechos Humanos (1948). Declaración Universal de Derechos Humanos. Recuperado de: https://www.un.org/es/universal-declaration-human-rights/

- Organización Internacional del Trabajo (1952) Convenio sobre la seguridad social (norma mínima). Recuperado de: https://www.ilo.org/secsoc/areas-of-work/legal- advice/ WCMS_222058/lang--es/index.htm

Fecha de recepción: 23 de octubre de 2020

Fecha de aceptación:06 de noviembre de 2020 